\title{
Lutas pela história da saúde: perspectivas sobre as ciências sociais em saúde a partir da trajetória intelectual de Luiz Antonio de Castro Santos
}

\author{
Struggles for the history of health: perspectives on the \\ social sciences in health based on the intellectual \\ trajectory of Luiz Antonio de Castro Santos
}

Entrevista com

\section{Luiz Antonio de Castro} Santos ${ }^{i}$

'Professor visitante sênior, Universidade Estadual do Maranhão.

São Luís do Maranhão - MA - Brasil orcid.org/0000-0003-0872-4276

lacs1945@gmail.com

Concedida a

\section{Carlos Henrique}

Assunção Paivai

ii Pesquisador, Casa de Oswaldo

Cruz/Fiocruz.

Rio de Janeiro - RJ - Brasil

orcid.org/0000-0002-7478-9628

carlos.paiva@fiocruz.br

Fernando Pires-Alves ${ }^{i i i}$

iii Pesquisador, Casa de Oswaldo Cruz/Fiocruz.

Rio de Janeiro - RJ - Brasil

orcid.org/0000-0002-5091-9539

fernando.pires@fiocruz.br

\section{Luiz Antonio Teixeira ${ }^{i v}$}

iv Pesquisador, Casa de Oswaldo Cruz/Fiocruz.

Rio de Janeiro - RJ - Brasil

orcid.org/0000-0001-8871-0928

luiz.teixeira@fiocruz.br
PAIVA, Carlos Henrique Assunção; PIRES-ALVES, Fernando; TEIXEIRA, Luiz Antonio. Lutas pela história da saúde: perspectivas sobre as ciências sociais em saúde a partir da trajetória intelectual de Luiz Antonio de Castro Santos. História, Ciências, Saúde - Manguinhos, Rio de Janeiro, v.26, n.3, jul.-set. 2019, p.993-1012.

Resumo

A entrevista aborda os percursos que ligam as ciências sociais à saúde a partir da trajetória do sociólogo Luiz Antonio de Castro Santos. Participante ativo do processo de integração desses campos, Castro Santos contempla alguns dos desafios enfrentados em sua trajetória profissional como forma de abordar aproximações que nem sempre se revelaram desprovidas de tensões. Conversa rica em fatos e processos, Castro Santos situa alguns dos principais personagens e marcos de uma trajetória que trouxe contribuições tanto para as ciências sociais e a história como, principalmente, para as ciências da saúde.

Palavras-chave: saúde coletiva; história; história da saúde; ciências sociais; Luiz Antonio de Castro Santos (1945- ).

\section{Abstract}

This interview discusses the connections between social sciences and health, based on the trajectory of sociologist Luiz Antonio de Castro Santos. Castro Santos was an active participant in the process of integrating these fields, and considers some of the challenges he faced as a way of addressing approaches that were not always devoid of tension. In a conversation rich in facts and processes, Castro Santos describes some of the most important characters and landmarks from a trajectory that contributed to the social sciences and history, and especially to the health sciences.

Keywords: public health; history; history of health; social sciences; Luiz Antonio de Castro Santos (1945-). 
$\mathrm{N}$ os idos da década de 1980, quando a sociologia histórica pouco se voltava para as questões de saúde e a história do Brasil, limitando-se a analisar o período de atuação de Oswaldo Cruz no Rio de Janeiro, Luiz Antonio de Castro Santos produziu sua tese de doutorado sobre a reforma sanitária em São Paulo e na Bahia. Trabalho de fôlego, saído dos bancos da Universidade de Harvard, a tese, além de contribuir para a compreensão do processo de transformação da saúde e do saneamento como ideiasforça da formação de nossa nacionalidade, nos anos 1920, foi uma das precursoras da tematização da saúde como objeto de análise sócio-histórica no país. Desbravando um novo trajeto que unia a saúde à construção nacional, Castro Santos abriu o caminho também trilhado por importantes trabalhos sobre o tema, em especial os de Gilberto Hochman e Nísia Trindade Lima, na Casa de Oswaldo Cruz. Seu trabalho pioneiro foi a base da construção de um sólido edifício, hoje bem caracterizado pela produção acadêmica da instituição que sedia este periódico.

Tendo iniciado sua atividade profissional no Centro Brasileiro de Análise e Planejamento (Cebrap), Castro Santos migrou para o Instituto de Medicina Social da Universidade do Estado do Rio de Janeiro (IMS/Uerj) no fim da década de 1980, ajudando a pensar, com as ferramentas da sociologia histórica, os aspectos do passado que seriam analiticamente relevantes para as mudanças na saúde que então se anunciavam com o movimento sanitarista e a reforma sanitária. No IMS/Uerj, conduziu importantes pesquisas no campo da sociologia histórica da saúde. Estudos que abririam caminho para diversos pesquisadores que, desde então, voltaram-se para as diferentes relações entre nacionalismo e saúde pública, pensamento social e história das profissões de saúde no Brasil. Em 2015, já aposentado no IMS/Uerj, migrou para a cidade de Porto Seguro, Bahia, onde se envolveu com o inovador projeto da Universidade Federal do Sul da Bahia, então conduzido pelo professor Naomar de Almeida Filho.

Tão importante quanto o resumidíssimo relato sobre a vasta experiência e projeção de Castro Santos no campo da história da saúde é a observação da sua importância na conformação da Casa de Oswaldo Cruz - unidade da Fiocruz responsável por esta publicação. Sendo agente de formação de muitos de seus pesquisadores, participando de projetos, de eventos e de variadas formas que abririam espaço para diversas reflexões e ações, Luiz vem contribuindo de forma constante e segura com nossa unidade.

Por tudo isso, e em especial pelo valor afetivo que Luiz Antonio de Castro Santos tem para nós do Observatório História e Saúde da Casa de Oswaldo Cruz, procuramos, na entrevista que se segue, dar maior divulgação sobre sua experiência, que, de diversas maneiras, se confunde com o processo de integração das ciências humanas e sociais ao chamado campo da saúde coletiva.

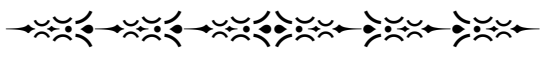


Carlos Henrique Assunção Paiva: O motivo central da nossa conversa é entender sua trajetória como parte de um processo que a gente chama de inserção das ciências sociais na saúde. A primeira coisa sobre a qual gostaria de te ouvir é justamente acerca da expressão "inserção das ciências sociais na saúde". É uma expressão muito mobilizada na literatura da saúde coletiva, quase um mantra, para referir o próprio processo de constituição do que seria um campo da saúde coletiva. Como é que você entende esse processo e quais seriam os seus principais marcos?

A minha entrada no Instituto de Medicina Social da Uerj, anos depois de meu doutoramento, foi curiosa, porque a minha preocupação com a saúde, do ponto de vista histórico, tem a ver com antigos antecedentes, com a minha graduação em sociologia e a especialização em demografia social. Fiz especialização em demografia numa época em que a gente já tinha dificuldade de entrar no mercado de trabalho como sociólogo. Então, em 1971, o Centro Latino-Americano de Demografia (Celade) junto com a Pontifícia Universidade Católica do Rio (PUC-Rio), pela iniciativa de Helena Lewin, ${ }^{1}$ uma grande empreendedora da geração de ciências sociais com outros campos, organizou um programa de especialização em demografia no campus da Gávea, em horário integral, ministrado por professores vindos de Santiago do Chile. Dois anos depois, com uma formação sólida na graduação em sociologia na PUC e a especialização em demografia pelo Celade, rumei para minha pós-graduação em Harvard, com bolsa (inicialmente) de um programa de população para países subdesenvolvidos. Foi um longo período, durante um mestrado na Escola de Saúde Pública (School of Public Health) de Harvard e, em seguida, no Departamento de Sociologia, já no doutorado. Foi um longo período, particularmente porque tirei uma licença do programa de doutorado por vários anos, entre 1979 e 1983 ou 1984. Permaneci no Brasil, em parte porque o CNPq, naquela época, abria possibilidade para doutorandos ministrarem cursos em regiões afastadas (eu cheguei a ser convidado para a Universidade Federal do Rio Grande do Norte) e em parte porque não havia camisas de força, como os tais quatro anos de hoje, no Brasil e em muitos outros países, para que concluíssemos nossas teses. Esses graus de liberdade nos davam tal lastro no doutoramento que nossas teses acabavam por ser muito boas e tornavam sem sentido os tais "pós-doutorados" modernos. Eram outros tempos. Então, quando voltei dos EUA, voltei com uma tese de história da saúde no Brasil, sob a orientação e coorientação de gente muito boa e talvez com um "achado" ou conclusão pioneira, a de que a saúde foi importante no Brasil desde os primeiros tempos republicanos porque teve aspectos ligados à construção da própria nação.

Fernando Pires-Alves: Mas aí você já está falando do seu doutoramento, não é?

Estou falando do que me levou ao doutoramento voltado para temas de história e sociologia da saúde. O fato de ter feito a especialização com o Centro Latino-americano de Demografia abriu espaço para minha "aventura do exílio", como afirmou Gilberto Freyre certa vez, durante o regime Vargas. Então busquei o mestrado na Escola de Saúde Pública de Harvard com a preocupação de estudar mortalidade e demografia social, temas que me levaram a cruzar o Charles River ${ }^{2}$ em 1974 e cursar o doutorado em sociologia. 


\section{Carlos Henrique Assunção Paiva: Quem eram os orientadores no doutorado em sociologia?}

Paul Starr ${ }^{3}$ foi um conselheiro, um orientador excelente. Era professor associado. E tive a enorme satisfação de ser acompanhado por um "coorientador", Gösta Esping-Andersen, ${ }^{4}$ sociólogo dinamarquês que tinha acabado de chegar a Harvard, extremamente dedicado ao trabalho de orientação; foi também um conselheiro exemplar.

Bom, antes deles, o programa de mestrado no campus de Boston não tinha sido uma experiência fácil. Havia pontos fortes no programa, mas me sentia como meus colegas asiáticos e africanos - a grande maioria dos estudantes -, como um grupo de "segunda classe". Lembro-me de ter contado isso há muitos anos para Nísia Trindade Lima, quando retornei ao Brasil. Cheguei lá felicíssimo, não precisava nem de bolsa do CNPq, porque a universidade tinha suas próprias fontes de financiamento para "estudantes do Terceiro Mundo". Mas surgiu logo uma sequência de contratempos. Já nos primeiros dias, o coordenador do programa me chamou: "Bom, você, Castro Santos, vai trabalhar com aborto"; respondi: "Vou trabalhar sim, como uma das disciplinas ou montar algum seminário, será um prazer". [Ele disse:] "Não, você não entendeu, sua dissertação vai ser sobre aborto". Eu falei, "Professor fulano, está me obrigando a escolher um tema de dissertação?". E ele disse "sim, e você vai trabalhar com doutor sicrano", um veterinário, recém-doutor pela própria School of Public Health... "Eu me recuso. Eu não vim do Brasil pra ter alguém me dizendo qual o tema que eu vou trabalhar. Minha geração está combatendo ditadores lá no Brasil, correndo riscos terríveis, e nossos mestrados não são impositivos como aqui". "A sua bolsa tem certos requisitos", foi o que ouvi. Procurei então ajuda entre outros professores, dois deles demógrafos sociais, social demographers. Um deles era já um demógrafo respeitado, um sociólogo voltado para temas de sociologia urbana, Nathan Keyfitz. ${ }^{5}$ Keyfitz tinha um conhecimento bastante grande de América Latina e uma cabeça aberta, foi ele quem me afrouxou o laço. Perguntou: "Que tema você quer estudar?". "Quero estudar mortalidade e desigualdade social". E foi bastante solidário comigo, apoiou-me.

Perguntaram então se eu aceitava trabalhar o tema das migrações internacionais. Keyfitz me aconselhou a aceitar, acenando com meu doutorado, como se fosse um desagravo: "No departamento de Sociologia você terá inteira liberdade".

Luiz Antonio Teixeira: O que significou esse professor do programa de mestrado sugerir - era mais que sugestão - o tema de aborto? Era assim que as coisas funcionavam?

Era assim que as coisas funcionavam nas escolas de saúde pública criadas nos EUA com um foco nos países que hoje chamamos periféricos. Isso me deixou frustradíssimo, percebi que ali meus colegas da Índia, do México e sobretudo da África formavam uma maioria silenciosa, e parte dela, satisfeita por estar lá, como hoje há brasileiros felizes por viver em Miami. Para cada dez de nós, havia um americano. Isso me chamou atenção. Pensei "há algo estranho aqui". Havia bolsas, você terminava e tinha a certeza de poder permanecer nos EUA por mais tempo, para cursar o doutorado lá na Escola de Saúde Pública. Isso foi em 1973, o mestrado era de dois anos. 
Luiz Antonio Teixeira: Luiz, esse seria o momento em que o Population Council ${ }^{6}$ estava muito preocupado com a questão do crescimento populacional e fazia da natalidade e do aborto uma questão central?

Isso. Para entendermos melhor o que se passava no plano internacional, devemos pensar no plano local, na atuação militante, em plena ditadura, de uma grande figura humana e incomparável demógrafa, Elza Berquó. ${ }^{7}$ Elza acaba de completar 90 anos em total lucidez, homenageada em São Paulo no Cebrap por todos que trabalharam com ela desde a década de 1980. Estivemos juntos nos idos de 1985-1990, antes de me transferir de vez para o Rio de Janeiro. Pois foi justamente Elza Berquó quem chamou atenção, em plena ditadura, para o movimento de laqueaduras, especialmente no estado de São Paulo, com recursos da Bemfam (Bem-estar Familiar no Brasil). Bemfam, leia-se nessa época Population Council e leia-se Rockefeller Foundation - não a Rockefeller dos anos anteriores à Segunda Guerra, quando revelou uma atuação absolutamente ética em relação à pesquisa científica, às populações locais e aos pesquisadores de países como o Brasil. Os tempos de pós-guerra foram outros, sombrios. Nelson Rockefeller passou a imiscuir-se politicamente na conduta da Fundação (que até então atuava de modo independente em relação à família) e foi um desastre. A bem dizer, desde meu tempo no curso do Celade [Centro Latino-Americano e Caribenho de Demografia] eu sabia, pela voz de alguns de nossos mestres, que havia um movimento internacional de propagação da ideologia de controle populacional voltada para os países subdesenvolvidos. O médico John B. Wyon, ${ }^{8}$ professor da School of Public Health, em Harvard, desde os anos de 1970 (e que foi quem me disse "você vai estudar aborto"), dirigiu na Índia o famoso Khanna Study, que era um estudo do impacto da distribuição das pílulas, entre outras estratégias anticoncepcionais, em alguns povoados. Era um estudo comparativo, de alguns povoados na Índia, mas o mais importante foi o que deu origem a esse nome Khanna Study. ${ }^{9}$ Então sabia de quem se tratava. Fui me mobilizando politicamente contra esse grupo dentro da Escola de Saúde Pública e isso teve um preço. Eu me tornei um problema dentro da Escola porque nas reuniões, nos seminários abertos, eu levantava a mão e falava da Igreja católica na América Latina, sobre o padre Hélder Câmara ${ }^{10}$ e sua luta contra as políticas de controle populacional. Ainda por volta de 1974, o departamento de population studies lançou uma espécie de edital para alunos do terceiro mundo que tivessem interesse em participar de um encontro de jovens universitários em Washington, numa casa aliás belíssima, para debater temas de população, "crescimento demográfico" etc. Eu me candidatei, alinhavei algumas ideias como uma proposta e... fui escolhido. Fui o único estudante da School of Public Health de Harvard. Quando cheguei, percebi que haviam cometido um erro. A comissão de seleção era nacional, não tiveram muito controle sobre "quem era quem" entre os alunos. Observaram, creio, a origem regional (América Latina, África, Oceania), sem atentar para os países de origem. Traídos por meu sobrenome ("Santos" foi lido como "Sanchez"), escolheram-me para uma apresentação oral: "Você vai falar sobre o plano de controle populacional na Colômbia, já que vem de lá". "Mas eu não sou colombiano, sou brasileiro". "You are not Sanchez?". "No, I'm Santos" [risos]. Só me lembro de terem remarcado minha fala, que foi cancelada "informalmente". Quando voltei a Boston, John Wyon me chamou, num tom conciliador: 
"Soubemos que você teve uma participação muito importante nesse evento". Tudo isso se deu logo nos primeiros meses de minha entrada no mestrado. "Sabemos que você veio pra cá com conhecimento que poucos colegas seus tem de demografia". Eu: "Pois não". Creio que eles pediram a ajuda e conselhos ao professor Keyfitz, pois reabriram meu histórico com o curso intensivo de especialização no Centro Latino-americano de Demografia e, para minha surpresa, concederam-me o direito de cursar o mestrado não em dois, mas em um ano apenas! Ou seja, eu terminei em um ano um programa de dois anos. E a direção do programa se livrou de um criador de casos, um brasileiro "insurgente".

Carlos Henrique Assunção Paiva: Só para situar, Luiz, isso foi em que ano?

Iniciozinho de 1974. Novamente, a solidariedade de Keyfitz foi fundamental. Pois deu-se o seguinte: o diretor do programa de bolsas (ao qual eu estava ligado) alertou-me: "Sei que você está se candidatando ao doutorado em sociologia aqui em Harvard e faz parte do seu contrato conosco você voltar ao Brasil no fim do mestrado". Ou seja, nada de doutorado. Eu falei: "Isso não está escrito em documento nenhum". "Mas isso ficou definido e acertado em minha visita ao Brasil, quando estava divulgando nosso programa de estudos populacionais". Naquele momento ficou clara a preocupação do retorno para "pregar" o evangelho ou a doutrina do controle populacional. Eu disse: "Olha, eu não vou voltar". E ele: "Você vai ter dificuldades aqui nos EUA". Foi então que novamente procurei o professor Keyfitz. Ele foi genial. Disse: "Faça o seu application, preencha tudo, faça o seu projeto de estudos em sociologia direitinho sem levar nada disso em conta, porque isso não vai pesar contra você e nem a seu favor". Segui o que recomendou. Passou-se o tempo regulamentar de seleção e foi ele, pessoalmente, quem me deu a boa notícia, em nossa sala de aulas: "Mr. Castro Santos, you have been accepted". E me cumprimentou fraternalmente. E percebi, naquele momento, como pessoas solidárias, pessoas do bem, são importantes para reverter decisões arbitrárias e sobrepujá-las.

Fernando Pires-Alves: E ele era do mesmo programa?

Ele era do mesmo programa de Population Studies, mas pertencia também, por sua biografia excepcional, a um segundo programa, que era o de doutorado no Departamento de Sociologia. Era um programa do outro lado do Charles River, que divide as cidades de Boston e Cambridge. Percebi, em pouco tempo, que a mudança institucional seria decisiva para mim, não havia sido apenas um "deslocamento geográfico"... Keyfitz era respeitadíssimo, eu diria que figurava entre os maiores demógrafos americanos. Muito simpático, volta e meia eu cruzava com ele andando de bicicleta em Harvard Square, já tinha quase a minha idade hoje, e ainda viveu mais uns vinte e tantos anos. Talvez um pouco mais moço que eu hoje, talvez sessenta e poucos anos quando eu o conheci.

Luiz Antonio Teixeira: Luiz, daí você entra no seu doutorado.

Aí eu me submeti ao processo de seleção, eram poucas vagas. Nesse momento, minha esposa à época, Maria Helena Castro Santos, ${ }^{11}$ candidatou-se a uma bolsa de doutorado 
no MIT [Massachusetts Institute of Technology], uma bolsa da Fundação Ford e foi aceita para ciência política. Então, tínhamos minha bolsa pelo CNPq (ao fim do mestrado) e sua bolsa, pela Fundação Ford, para cursar o doutorado no MIT.

Fernando Pires-Alves: Época de ouro.

Época de ouro, para quem estivesse no exterior. Não creio que brasileiros em outros países, na Europa, tivessem os mesmos recursos que as universidades nos possibilitavam nos EUA. Mas nem tudo brilhava... Não tínhamos filhos. Alguns de nós, na pequena comunidade de brasileiros em Cambridge, Massachusetts, eram "chefes de família" por vezes com dois, três filhos. A situação financeira era apertada. Mas no meu caso, em particular, uma oportunidade "de ouro" de fato surgiu. Tivemos naquela época a possibilidade de os alunos de doutorado darem aula para os alunos do College de Harvard, e havia uma bolsa de auxílio que nos era destinada. Eu submeti um projeto para os estudantes, selecionado entre os inúmeros projetos de meus colegas. Propus estudarmos as revistas inglesas consultadas por Marx e Engels sobre as questões de população, saúde pública (cólera, sobretudo) e classes trabalhadoras durante o século XIX. Eram textos reunidos em uma coleção publicada em 1973, com centenas de artigos do The Edinburgh Review, The Westminster Review e outras revistas inglesas, que cobriam o período 1802-1870 e estavam disponíveis aos estudantes na fantástica Widener Library, em Harvard Yard. Cito esse tema de meus seminários porque aqueles textos hoje em dia devem ser de fácil acesso na Biblioteca de Manguinhos. E seriam tema interessantíssimo para uma dissertação ou tese de alunos da Fiocruz.

Fernando Pires-Alves: E como era o campo da história da saúde, já que você optou por um trabalho que era um pouco sobre história da saúde?

Era sociologia da saúde a linha central no campo. A história era um pouco minha própria escolha, além do acompanhamento ou bons papos com historiadores nos outros departamentos. Creio que o contato mais proveitoso, inclusive pela leitura de um livro publicado pela autora em 1972 (portanto acabava de ser lançado), foi com uma pessoa maravilhosa do Departamento de História, Barbara Gutman Rosenkrantz. ${ }^{12}$ Filha de intelectuais, tinha os seus 45 anos na época. Ela era professora de History of Science and Public Health em Harvard. Creio que Public health and the State: changing views in Massachusetts, 1832-1936 (Rosenkrantz, 1972), sua obra principal, indicou-me caminhos promissores para trabalhar o tema da relação entre governo federal e estados (Bahia e São Paulo, em minha própria tese), e a relação entre governos estaduais e políticas de saúde. Devo muito a Barbara, pela trama que construí sobre a atuação dos estados (nos dois níveis, federal e estadual) em minha tese. Lembro-me que fui conversar com ela por sugestão do Paul Starr. Paul não foi apenas um ótimo orientador de minha tese, mas tinha também uma leitura muito cultivada, muito trabalhada, de história da saúde. Seu "livro de ouro", se posso chamar assim, foi publicado em 1982, The social transformation of American medicine (Starr, 1982), cujo recorte histórico, desde o século XIX, considero imperdível. Acresce que a interpretação histórica é também um trabalho de mestre naquele livro. Não foi traduzido para o português até hoje. 
Fernando Pires-Alves: Não foi. Tem uma edição espanhola.

Isso mesmo, a edição espanhola está bem trabalhada, ainda que o título em espanhol - a meu ver infeliz - não indique aos leitores, com alguma precisão, os temas tratados. Entre os textos históricos que me inspiraram muito, além dos citados, os livros de George Rosen, ${ }^{13}$ médico nova-iorquino e historiador de primeira grandeza, foram outra descoberta, por sugestão de Paul Starr e de Barbara Rosenkrantz.

Luiz Antonio Teixeira: Essa literatura, esses autores, eram trabalhados nos cursos de sociologia e de história também?

Sim, mas tinham um lugar quase periférico. Algo que até hoje perdura. Aliás, se formos ver o lugar da revista [História, Ciências, Saúde:] Manguinhos na classificação das próprias áreas... não está como A1 em saúde coletiva.

Carlos Henrique Assunção Paiva: Não tem também nenhuma revista brasileira que seja A1 em saúde coletiva.

Mas então são nossos colegas da epidemiologia que definem isso. Algum tempo atrás, uma newsletter da American Sociological Association publicou um fórum sobre saúde e sociedade, algo sobre fatores de mortalidade. E a discussão era toda epidemiológica, isso num veículo da própria American Sociological Association. Então eu escrevi ao coordenador do fórum com uma matéria crítica que intitulei "First-rate sociology, or second-hand epidemiology?". Talvez fosse um convite para nossas tribos da saúde coletiva no Brasil resgatarem o devido lugar da sociologia da saúde e, em particular, da necessidade de pensarmos historicamente. Digo isso sem nenhum viés, porque, desse meu tempo na Escola de Saúde Pública em Harvard, ficou um legado interessante, eu diria bastante sólido, de um curso de epidemiologia de um semestre que era obrigatório para os alunos do mestrado. Eles eram ótimos professores, tanto assim que o meu contato com Naomar de Almeida ${ }^{14}$ - excelente reitor da Universidade Federal do Sul da Bahia e que me abriu as portas para concorrer a uma bolsa de visitante - se tornou possível graças àquela formação em epidemiologia. Por sua vez, Naomar, médico, psiquiatra e epidemiólogo de primeira, é exemplo de abertura para o campo das ciências humanas. Nos seus escritos, as ciências humanas não ocupam um lugar, digamos, subalterno. Mas se olharmos com atenção os trabalhos da seção de Medical Sociology nos congressos da American Sociological Association, não é raro sentirmos que estamos diante de uma "sociologia de segunda classe", nenhuma história da saúde, nenhum diálogo com os clássicos. Talvez a saúde coletiva no Brasil esteja marcada, apesar de ter grupos excelentes, por uma narrativa antes de tudo epidemiológica, na qual a narrativa e a interpretação sociológicas têm desempenho menor.

Luiz Antonio Teixeira: Luiz, a gente até agora centrou na sua trajetória e chegamos ao doutorado.

Isso, recuperemos a linha do doutorado. Quando eu voltei dos EUA, senti imediatamente um vazio, uma espécie de desprestígio pelo tema que eu tinha escolhido para minha tese. Em 1979, se pensarmos em revistas de sociologia, creio que apenas a Novos Estudos, do 
Cebrap, abria espaço considerável para questões de "saúde e sociedade", mas a história da saúde pública, na linha de um George Rosen, não tinha muita popularidade. E minha tese justamente centrava-se em processos históricos da saúde no Brasil. Não desisti, foi aqui no Rio de Janeiro, na revista Dados, do antigo Instituto Universitário de Pesquisas do Estado do Rio de Janeiro (Iuperj), por obra e graça (e competência editorial!) de Charles Pessanha, ${ }^{15}$ que traduzi e publiquei alguns capítulos da tese, particularmente sobre São Paulo e Bahia na Primeira República. Na época, não tive fôlego para traduzir toda a obra e hoje, passados anos e anos, temos no trabalho de Gilberto Hochman, A era do saneamento (1998), uma retomada, sólida e inspiradora, de questões que tratei na tese, que defendi em 1987. Uma questão importantíssima trabalhada por Gilberto em seu livro de 1998, a expansão do poder do Estado central desde os primeiros tempos republicanos (especialmente com Venceslau Brás na presidência) - ao mesmo tempo que os estados da federação, como São Paulo e Bahia, também se aparelhavam sobre os alicerces das políticas e instituições de saúde - havia sido um ponto de honra em minha tese. Gilberto retomou esse fio da meada, sobre a construção histórica de políticas estatais. Na Casa de Oswaldo Cruz os processos históricos ganharam seu lugar de destaque, com trabalhos de pesquisadores como Nísia Trindade Lima, Marcos Chor Maio e Gilberto Hochman - um naipe de gente de primeira grandeza, fortalecida ainda com jovens historiadores. A revista História, Ciências, Saúde-Manguinhos foi o desaguadouro de tantos trabalhos da Casa, além de contribuições nacionais e internacionais.

Nessa linha de importantes trabalhos históricos sobre a saúde, um ponto, quanto à interpretação, tem me incomodado bastante. Trata-se da atribuição frequente de "débito" de nossos trabalhos a certo "institucionalismo", no sabor tradicional ou "neoinstitucionalismo" [risos]. Muito simplesmente, quando aventamos a possibilidade de débito, cometemos enorme equívoco. Os nossos colegas gringos, na área de patente de fármacos, têm diversas bandeiras fincadas e propaladas como pioneiras e são mestres de estratégia e marketing. Em territórios de ciências humanas, tudo que conhecemos sob a bandeira de "sociologia histórica da saúde" virou institucionalismos. No caso dos institucionalismos, não é culpa deles, é ingenuidade nossa. Eles não leem português, nem se interessam em ler nossos trabalhos em inglês, quando traduzidos. O clássico de Victor Nunes Leal (2012), de 1948, foi traduzido e publicado pela Cambridge University Press em 1977. Seria um "institucionalista" avant la lettre? Em 1977 os "institucionalistas" de lá estavam ainda cursando seus doutoramentos ou eram recém-doutores... Não sabem até hoje que, há "séculos", trabalhos de Faoro, ${ }^{16}$ Wanderley Guilherme dos Santos, ${ }^{17}$ Fernando Henrique Cardoso ${ }^{18}$ (primeira fase) e Octavio Ianni ${ }^{19}$ já eram "institucionalistas" antes de Theda Skocpol, ${ }^{20}$ Rosemary C.R. Taylor ${ }^{21}$ ou Ellen Immergut ${ }^{22}$ publicarem qualquer coisa. Ellen, aliás, foi minha brilhante colega no doutorado em Harvard, enquanto as primeiras eram recém-doutoras. Estou certo de que, desde Faoro e Victor Nunes Leal, nossos autores achariam graça em alguém propalar, como um achado "institucionalista", que "políticas geram políticas"... Bem, so much for that. Isso me preocupou tanto que cheguei a escrever um texto sobre o chamado testamento de Vargas nas políticas de saúde, com o subtítulo "Institucionalismos à parte". Publiquei como um capítulo numa coletânea que organizei para a EdUerj, em 2013, Contrapontos: ensaios sobre saúde e sociedade. 
Fernando Pires-Alves: E sua trajetória profissional ao terminar o doutorado, como foi sua inserção brasileira, por assim dizer?

De fato não havia terminado o doutorado quando retornei em 1979. Tinha feito o qualifying, tinha feito todo o trabalho de coleta de dados históricos, de análise das fontes, de exame da literatura etc. Retornei porque havia sinais de mudanças políticas, de abertura política no horizonte, e eu pensava em me fixar, ser pesquisador, ingressar no mercado acadêmico, algo assim. Quando cheguei, ou algum tempo depois, em 1980 ou 1981, recebi um convite para um estágio como sociólogo na Fundação de Tecnologia Industrial, no Rio de Janeiro, órgão do Ministério da Indústria e Comércio, se bem me lembro. Havia interesse em pesquisas tecnológicas sobre o carvão do babaçu. A produção do coco e a extração do carvão, na verdade, eram algo artesanal, que envolvia as mulheres quebradeiras, verdadeiras lutadoras, exploradas por pequenos comerciantes locais. Os dirigentes da Fundação queriam conhecer melhor o universo das relações de produção do coco babaçu, por assim dizer. Nisso entrava o trabalho de um sociólogo. Tive uma experiência fantástica com as quebradeiras por causa das possibilidades industriais de exploração do babaçu, que era uma coisa que estava pipocando inclusive pelo lado do IPT lá de São Paulo, na fabricação de máquinas de aproveitamento da noz do babaçu para...

Fernando Pires-Alves: Isso onde? Maranhão? Piauí?

Maranhão e Piauí. Para a extração do carvão vegetal. A Fundação de Tecnologia Industrial tinha um interesse focalizado no aspecto industrial, mas eu encarava a viagem para a qual me comissionaram, ao Norte, como sociólogo, como uma experiência de contato com uma região e um coletivo de mulheres trabalhadoras do campo. Meu primeiro contato com as quebradeiras, na região de São Luís, deu-se em 1981, num encontro interestadual muito bonito, para o qual me convidou Alfredo Wagner Berno de Almeida, ${ }^{23}$ um antropólogo de mãos cheias, dos maiores estudiosos de populações da nova cartografia social da Amazônia, projeto que ele comanda há anos, em Manaus. Meu contato com as quebradeiras frutificou ao longo dos anos. Escrevi um ensaio sobre a experiência de vida, a luta pela coleta livre e a relação com a saúde das quebradeiras. Recentemente, revi o texto antigo para uma coletânea publicada pela Hucitec, organizada por mim e por Lina Faria, ${ }^{24}$ Saúde, sociedade, protagonismos. Foi justamente o protagonismo do movimento das quebradeiras que deu origem ao ensaio que intitulei "A vez da mulher camponesa: movimento social, identidade e saúde no Maranhão".

Carlos Henrique Assunção Paiva: No seu retorno, parece que estava no seu horizonte profissional alguma coisa que nós chamaríamos de sociologia da saúde. O texto sobre as quebradeiras de babaçu reflete essa vertente? Esse campo já se avizinhava?

Sim. Nunca abandonei a ideia. Aliás, boa parte da liderança das quebradeiras, na verdade algumas líderes, era composta por agentes comunitárias da saúde. Eram os primeiros programas bem-sucedidos com ACS, os agentes comunitários de saúde. 
Fernando Pires-Alves: Você se autorreferia como um sociólogo da saúde?

Sempre. Sempre.

Fernando Pires-Alves: Quem habitava esse campo à época?

Havia figuras importantes, verdadeiras referências. Paul Singer, ${ }^{25}$ um economista e sociólogo com sólido e reconhecido lastro intelectual, que conheci no Cebrap. Isso, quando retornei pela segunda vez dos EUA, para onde fui finalizar a tese de doutoramento. Terminada e aprovada, já no Brasil, andei por Seca (com "s") e Meca, fui convidado para trabalhar no IBGE presidido pelo professor Isaac [Kerstenetzky], ${ }^{26}$ mas não pude assumir. Num congresso da Abep [Associação Brasileira de Estudos Populacionais], creio que em 1983, recebi o convite generoso de Elza Berquó para ingressar como pesquisador do Cebrap, em São Paulo. Tanto pelo lado da demografia como pelo lado da saúde coletiva - ou mesmo pelo caminho tradicional da saúde pública -, houve inúmeros pontos de interlocução com Elza. Já no Cebrap, em poucos meses minha amizade com Ruth Cardoso ${ }^{27}$ resultou de um convívio intelectual prazeroso e estimulante. Em 1983, Ruth havia lançado um desafio nessa discussão sobre demografia e saúde reprodutiva, dizendo em poucas palavras: "A fertilidade é nossa. Não é a esquerda que vai definir quantos filhos nós vamos ter e muito menos a direita". O artigo foi um divisor de águas dentro do movimento feminista. E havia a denúncia de laqueaduras criminosas, contra as quais Elza Berquó se posicionou com firmeza.

Carlos Henrique Assunção Paiva: Há uma narrativa, presente em trabalhos como os do Everardo Nunes, que nos diz que a saúde coletiva seria fruto de um processo relativamente linear, cujas origens estão em iniciativas dos anos 1950, como os Departamentos de Medicina Preventiva e Social, e também de uma antropologia da saúde. Por que trato disso? É que imagino você como um sociólogo da saúde, mas sobretudo como um sociólogo, isto é, como alguém cuja origem remonta às ciências sociais. Você não desembarcou na sociologia vindo da área da saúde. Seu percurso foi contrário ao de muitos que hoje frequentam o campo da saúde coletiva: você se forma nas ciências sociais e só depois caminha em direção à saúde, certo? Como sociólogo especializado, vamos chamar assim, nos assuntos da saúde, como você se percebe na área maior da sociologia? Naquela época, qual o diálogo da sociologia com a saúde?

Pequeno. O próprio Everardo ${ }^{28}$ não é sociólogo de formação. A medicina preventiva tinha uma ligação, a meu ver, um pouco subalterna em relação à epidemiologia. Ou então, como Juan César Garcia, ${ }^{29}$ uma ligação complicada com o marxismo. Juan César é uma referência obrigatória, mas faltou-lhe a leitura da obra de nosso maior marxista, Florestan Fernandes, ${ }^{30}$ para abrandar ou qualificar sua crítica ao funcionalismo como método legítimo de interpretação. Penso especialmente no livro Circuito fechado, de Florestan. Cecília Donnangelo ${ }^{31}$ foi uma socióloga tarimbada, que durante algum tempo julguei que fosse médica, o mesmo ocorrendo com minha convivência inicial com Madel Luz, ${ }^{32}$ outra referência fundamental na área de saúde coletiva. Diferentemente da professora Madel, cujos trabalhos foram muito lidos, parece-me que Donnangelo tornou-se um ícone, 
antes pelo caminho teórico que seguiu (referendado e legitimado por seu orientador, Luiz Pereira, ${ }^{33}$ numa fase, a meu ver, infeliz de sua maturação teórica como marxista althusseriano), do que pela divulgação de sua obra. Influências intelectuais entre nós por vezes operam como fatores limitantes, em vez de nos prepararem para um voo livre. Não teria sido esse o resultado infeliz da influência de Althusser sobre a obra de Luiz Pereira e, de quebra, sobre a obra de Donnangelo? Até certo ponto, o desconhecimento de história da saúde pública antes de Vargas levou-a a obscurecer aquela fase, em que as "dimensões técnicas e sociais" do trabalho médico no Brasil eram bem distintas do cenário urbano-industrial. A "produção estatal" de serviços médicos nas áreas rurais, para citarmos um fenômeno importante de atuação de gerações de sanitaristas, é praticamente desconsiderada em seus trabalhos. Considero imprescindível a leitura de Viagem, experiência e memória: narrativas de profissionais da saúde pública dos anos 30, de Neiva Vieira da Cunha (2005), obra premiada pela Anpocs, como um necessário contraponto aos escritos de Donnangelo, recortados sob a luz da dinâmica capital e trabalho, exploração de mão de obra, mais-valia etc. Falei sobre isso em recente palestra no Instituto de Saúde Coletiva, na Ufba, aos alunos do mestrado e doutorado de Luís Eugênio. ${ }^{34}$ Se pensarmos na contribuição de Neiva Vieira da Cunha, ${ }^{35}$ ao discutir o "espírito do sanitarismo rural como missão e projeto" entre velhos militantes da saúde pública, há um evidente contraste com as dimensões técnicas e sociais na fase urbano-industrial capitalista do mercado de trabalho médico e de saúde pública. Note-se um aparente paradoxo: as reflexões de Cecília se tornam cada vez mais atuais, cada vez mais finas, à medida que se aprofunda a crise do Brasil capitalista e do complexo médico-industrial em tempos recentes; e, contraditoriamente, os tempos idos do sanitarismo, sobretudo em sua vertente rural, apenas se recuperam sob imensos obstáculos, nas periferias e quebradas de nosso país, ainda não resgatadas para valer pelo SUS.

Fernando Pires-Alves: Mas como é que Donnangelo se encaixa com relação a esse tipo de periferia social no campo do trabalho em saúde?

Se entendermos por periferia tudo que se fazia de sanitarismo nas áreas "marginais ao capital", a obra de Donnangelo me pareceu sempre alheia àquele campo da saúde. O que tínhamos, no espaço urbano das classes profissionais organizadas, a partir de Vargas, era uma saúde pública voltada para aquelas classes. Donnangelo estava preocupada com os profissionais de saúde como uma categoria que tinha que se afirmar diante do capital. Isso é o que nós temos até hoje. É impressionante o corporativismo entre médicos e profissionais de saúde de modo geral, é impressionante.

Luiz Antonio Teixeira: Luiz, você está falando da Donnangelo que você leu na época de seus trabalhos ou da Donnangelo que você conhece depois?

Mais tarde, quando decidi buscar as razões de seu silêncio sobre o movimento sanitarista anterior a Vargas, na época em que postos de "profilaxia rural", Brasil afora, mantinham médicos inspetores de saúde desligados do corporativismo. 
Fernando Pires-Alves: Luiz, seu orientador, Paul Starr, produziu um livro de grande sucesso editorial, o que significou isso na virada para os anos 1980? Era preciso que a medicina representasse um tema assim, de atração para a opinião pública, não?

Mas seu livro merecia maior atração. O grande sucesso dele é a elegância da escrita e a capacidade de passar para os norte-americanos a ideia de que num livro você pode entender a história da medicina e toda a história dos EUA. A medicina é a profissão mais importante dos EUA desde 1848, quando a associação médica americana foi criada. Nós estávamos aqui engatinhando na pesquisa nas faculdades de medicina, as deles eram ainda piores - como indicava o famoso Relatório Flexner -, mas rapidamente eles ganharam uma qualidade que o Flexner conseguiu introduzir na pesquisa e no ensino. Esta é a parte boa do Flexner que nós ridiculamente ficamos demonizando e Starr recuperou com lucidez.

Fernando Pires-Alves: Luiz, eu estou entendendo que essa é uma leitura crítica de sua localização no campo da sociologia, de uma sociologia da saúde e até um olhar sobre o que foram os seus primeiros anos no ambiente da saúde coletiva. Eu queria que você narrasse um pouco isso. Quando você, digamos assim, vindo dessa sua inserção na sociologia da saúde, se insere na vida acadêmica.

Temos aí um cenário até certo ponto desfavorável para sociólogos da saúde. Talvez porque a perspectiva foucaultiana, a meu ver pouco sociológica, torna-se uma moeda de troca. A saúde se torna um campo meio "fora de lugar" na sociologia, nos congressos, nas palestras. Por exemplo, na área do CNPq, no chamado "Comitê de Assessoramento", quais são os sociólogos da saúde que são pesquisadores 1A? Creio que são poucos e desproporcionais em relação ao número de pesquisadores em sociologia da saúde. Mas eu quero chegar à saúde coletiva como campo de reflexão e pesquisas.

Luiz Antonio Teixeira: Fernando chamou atenção para a profissão: um sociólogo entrando no campo da saúde. Eu queria que você falasse sobre a questão da profissão, mas também das correntes de pensamento. Na sua aproximação com o campo da saúde coletiva, quais eram as correntes de pensamento que estavam de alguma maneira governando as análises?

O marxismo, sem dúvida.

Carlos Henrique Assunção Paiva: Como é que se dá a sua aproximação com essas correntes?

Quero distinguir o que eu chamaria de "marxismo dos médicos", distantes das correntes mais fecundas do marxismo europeu. O mesmo valeria para o uso meio pasteurizado de Foucault, isto é, a medicina e a saúde vistas como dispositivos de controle e disciplina dos corpos etc. Se levássemos a análise marxista simplista à saúde, qualquer avanço ou conquista no campo da saúde seria interpretado como uma "estratégia do capital". De modo similar, avanços ou conquistas, digamos, na saúde materno-infantil, seriam logo interpretados como "dispositivos de controle dos corpos" por foucautianos apalermados. Foi uma aproximação dura, difícil. Eu entrei no IMS em 1987, vindo do Cebrap, que só deixei de fato anos depois e de onde eu tirava as minhas turbinas, as minhas forças de 
resistência a diálogos empobrecidos. O diálogo e os debates que eu havia tido no Cebrap durante cinco anos eram de uma efervescência enorme, todo mundo lia tudo. Líamos de tal maneira que hoje em dia não sobraria tempo para facebooks. Um nível de leitura e debates fantástico. Fantástico.

Luiz Antonio Teixeira: Nessa época, quem estava entrando no IMS que era não médico? Digamos na sua geração, que estava ingressando.

Os antropólogos, mas estavam em outro departamento. Sérgio Carrara, ${ }^{36}$ um ou dois anos antes de mim, Maria Andrea Loyola, ${ }^{37}$ que foi quem me atraiu para a Uerj. Ela tinha uma participação ativa no Cebrap, eu devo isso à Maria Andrea.

Luis Antonio Teixeira: Luiz, insistindo nessa clivagem que você apontou no IMS: diferenças de grupos e como alguns tiveram mais proeminência que outros. Você acha que em alguma medida isso não estaria relacionado com o campo da saúde pública? Com o fato de alguns estarem lidando com temas mais aplicados. Quando passei pelo IMS, uma observação que fiz é que quem trabalhava em termos de maior aplicabilidade, por exemplo, a Madel discutindo a questão da homeopatia, ou mesmo o pessoal da economia, tinha propostas mais fortes, eram pessoas que tinham visibilidade. Estando num campo mais teórico, sociológico e histórico principalmente, estavam mais distantes. Você não acha isso também?

Eu acho que você tem razão. Havia problemas de redes distintas, então havia redes que tinham mais preponderância.

Carlos Henrique Assunção Paiva: Luiz, eu queria retomar uma questão. Desde o início dessa conversa, falamos da inserção das ciências sociais na saúde, da produção de conhecimento nessa área, a partir dos enfoques da sociologia e da antropologia, sobretudo. Eu queria introduzir um elemento nesse raciocínio: queria pensar em ciência social aplicada, na formulação de políticas de saúde, por exemplo. A título de exemplo, vieram à cabeça o Sesp $p^{38}$ e a figura do antropólogo e educador Charles Wagley, ${ }^{39}$ que viera da Universidade de Columbia. Enfim, o que a gente consegue perceber como marcos mais importantes num processo que considere as ciências sociais na sua aplicação ou contribuição para o desenvolvimento de políticas de saúde?

Bom, eu tenho a impressão que a vocação do Sesp nunca se perdeu. Nunca se perdeu. Se Arouca $^{40}$ estivesse vivo, acho que essa seria uma boa pergunta para ele. Essas jovens médicas, minhas alunas na Bahia, estão cursando o mestrado profissional em saúde, a linguagem delas é uma linguagem de movimento social e de participação e respeito por essas camadas marginais, como nos tempos do Sesp. Elas falam a língua dessa população, estudada desde os anos 1960 na América Latina pelo sociólogo argentino José Nun. ${ }^{41}$ No entanto, quando vemos os movimentos de base sindical, corporativa ou associativa, como no caso da Andes (Sindicato Nacional dos Docentes das Instituições de Ensino Superior), em termos políticos mais organizados, você sente o fosso com essa população periférica, o fosso está no nosso descaso com a educação pública, com a escola pública, com os jovens que preocupavam nosso Darcy Ribeiro. ${ }^{42}$ 
Fernando Pires-Alves: Você está fazendo um diagnóstico, num certo sentido rigoroso, de uma certa cena institucional brasileira, e sobretudo de sua crítica às lideranças do campo progressista e sua incapacidade de produzir respostas. A minha pergunta é: como isso pode ser traduzido numa perspectiva um pouco mais programática, numa agenda de pesquisa para o campo da saúde coletiva? Do ponto de vista da eleição de temas, o que pode ser feito? De que maneira esse diagnóstico pode orientar uma formulação programática para um campo como o da saúde coletiva ou das ciências sociais em saúde coletiva?

Educação pública de primeira qualidade, sobretudo. E educação para a saúde. Quer dizer, eu sempre penso na contribuição do Eduardo Stotz ${ }^{43}$ e de suas equipes de pesquisa. Eu acho que esse é um campo fundamental, especialmente para as chamadas "massas marginais" estudadas por José Nun e à margem do capital. Que nossos jovens dos morros e quebradas e suas famílias ainda desassistidas saibam o que é hanseníase, tuberculose, verminoses, febre amarela, dengue, zika. Que conheçam os direitos das colegas de escola e das meninas de bailes funk à saúde reprodutiva - que essas garotas saibam inclusive se proteger de uma gravidez precoce. Que o país tenha de fato uma formação desde a escola pública voltada para as doenças e direitos da população como um todo, sobretudo da população desassistida.

\section{Carlos Henrique Assunção Paiva: Doenças mais prevalentes?}

Às vezes nem são as mais prevalentes no Rio de Janeiro, mas a vivência de temas e problemas brasileiros é essencial, para que a garotada saiba o que significa a pegada genial do Assis Valente, ${ }^{44}$ "Brasil, esquentai vossos pandeiros, iluminai os terreiros". A falta de saneamento básico na periferia de nossas capitais é algo insustentável e inaceitável, com a omissão de vereadores, deputados estaduais e por aí afora. A meninada tem de saber que até hoje a hanseníase no Maranhão é um problema grave de abandono de nossas populações.

Fernando Pires-Alves: Desculpe. É uma questão de doença? De eleger essa ou aquela enfermidade? Ou são problemas de arranjo societário, de política elitista em torno da saúde para resolver mazelas que resultam da questão do atendimento, da questão do acesso e outras questões?

É claro que é o que você está dizendo. É a segunda coisa. É isso, mas, sem enfrentar questões da saúde coletiva, o conteúdo das políticas de inclusão vira "vamos dar carro para todo mundo", mais importante é o carro "que Deus me deu" do que exigir educação básica e políticas de respeito, de saúde e de transporte coletivo para trabalhadores e desempregados

Luiz Antonio Teixeira: Mas antes de avançar nesse ponto, quero que você continue numa outra direção. Eu queria que você falasse um pouco sobre como você vê a saúde pública no Brasil, o SUS, esse que a gente fala nas nossas aulas que é o máximo o tempo todo. Como você vê essa forma de se pensar a saúde pública no Brasil hoje?

Eu vejo com um olhar míope, eu fico todo o tempo pensando no que deixamos para atrás. Em nossa herança esquecida. Penso em um dos maiores conhecedores de conflitos agrários no Brasil, Alfredo Wagner Berno de Almeida, meu amigo há cinquenta anos, 
meu colega de turma, penso sempre nele, em João Pacheco de Oliveira, ${ }^{45}$ no Terri Valle de Aquino. ${ }^{46}$ A gente manteve uma irmandade de pensamento e de ação apesar de militar e compartilhar temas por vezes aparentemente distantes. Mas são sempre temas voltados para nossas populações excluídas de quaisquer direitos básicos. Como se o direito a torcer de modo ensandecido por um time de futebol ou orar em templos e igrejas para ter um carro fosse ao mesmo tempo a certeza de não participar de uma vida societária digna. Eu estou interessado nessa outra época, quando até sanitaristas tinham um espírito de missão. Dessa época promissora e abortada tratou Neiva Vieira da Cunha (2005) em seu livro. São tempos talvez recuperados pelos programas de saúde da família. Lina Faria está hoje dedicada a um trabalho no sul da Bahia com sua equipe da UFSB e prefeituras em áreas não assistidas pelos serviços ou postos de saúde. A equipe faz o trabalho que educadoras sanitárias, sobre quem Lina escreveu, desempenhavam no interior paulista desde os anos 1930. Então o nosso grande problema na saúde coletiva é o esquecimento da história. Falamos do trabalho das visitadoras hoje em dia e nos esquecemos de que tivemos uma tradição fortíssima nesse setor que foi deixada para trás com a urbanização da saúde.

Carlos Henrique Assunção Paiva: Luiz, eu quero te fazer duas perguntas. A primeira, você conseguiria identificar três ou quatro temas sobre os quais, na sua opinião, os historiadores da saúde deveriam se debruçar? A segunda pergunta: o que seria uma agenda para historiadores da saúde hoje? O que está por ser feito?

Primeiro, a história das epidemias que nós temos aqui na América Latina. Eu acho que foi parte da nossa agenda e talvez mais forte fora do Brasil do que aqui. Marcos Cueto é o grande empreendedor nessa temática. Temos que seguir suas trilhas. Há alguns anos, Lycurgo Santos Filho ${ }^{47}$ fez um trabalho interessante sobre a relação entre febre amarela, fazendeiros de café e vida urbana em Campinas, que sofreu três epidemias ainda no final do século XIX. Neiva Vieira da Cunha fez um esforço imenso nesse sentido, estudando a peste nos idos de 1940 no sertão nordestino. São exemplos promissores para o Brasil.

Em segundo lugar, precisamos atentar para protagonismos, para atores. Ainda hoje se fala na relação supostamente direta entre lutas sociais e reforma sanitária, algo que a rigor não se deu no Brasil. Se pensarmos, por exemplo, nas revoltas populares que sacudiram São Paulo em meados da Primeira República, as lutas se voltavam para questões de trabalho e denunciavam condições miseráveis das habitações coletivas, não para reivindicações por saúde. Esse é o meu ponto de divergência com boa parte da literatura. Como nos mostra Diego Armus ${ }^{48}$ em seus textos sobre a Argentina, no momento que aqui tínhamos a rebelião contra a vacina obrigatória, na mesma época as camadas populares na Argentina se posicionavam em defesa da vacina - a chamada vacina Pueyo. Diego rejeitou os excessos de certa leitura foucaultiana, que teria construído "um sujeito fundamentalmente passivo", sem qualquer protagonismo. Não se tratava, contudo, de que os trabalhadores e anarquistas tivessem chegado a influir de modo ponderável nos processos decisórios. O protagonismo era real, mas limitado. No Brasil, nessa mesma época, as políticas de saúde ainda emanavam "do alto", e não resultavam diretamente da participação ou de manifestos dos movimentos populares. 
Carlos Henrique Assunção Paiva: Qual é o papel da história? Qual é a importância de se conhecer determinados temas? O que esses temas suscitariam? Quais maneiras informam um debate mais contemporâneo no âmbito da saúde coletiva?

Eu acho que os nossos trabalhos, de Nísia Trindade Lima, ${ }^{49}$ de Gilberto Hochman, de Lina Faria e meus, entre tantos outros pesquisadores de primeira linha, remetem-nos à excelente produção da Casa de Oswaldo Cruz. Nossa produção, contudo, não tem o alcance que deveria ter. Poderia citar inúmeros exemplos da negligência aos estudos históricos, mas vou lembrar apenas um, que me parece exemplar. Numa mesa sobre história e saúde em um congresso da Associação Brasileira de Saúde Coletiva (Abrasco), há alguns anos, estávamos assistindo à fala de uma colega da Fiocruz. O tema começou bem, mas em certo momento ouvimos algo surpreendente: "Como vocês sabem, a grande virada que tivemos na história da saúde foi provocada pela caixa de aposentadoria e pensões e pelos movimentos pela saúde que estiveram associados ao início do governo Vargas". Todo nosso esforço de discutir os primeiros tempos do movimento sanitarista, que brotaram ainda na Primeira República, foi olimpicamente descartado. Eu estava sentado ao lado de Nísia, e não me contive: "Então tudo que nós escrevemos sobre os tempos anteriores a Vargas se perdeu?".

Finalizando, gostaria de agradecer imensamente a oportunidade desta entrevista, tão bem conduzida por vocês, meus colegas de pesquisa Carlos Henrique Assunção Paiva, Fernando Pires-Alves e Luiz Antonio Teixeira. Creio que nosso itinerário como pesquisadores tem inúmeros pontos em comum, e o foco desta entrevista centrou-se mais em despertar interesse por nossos caminhos e lutas pela história da saúde do que em trajetórias pessoais. Meu muito obrigado pela oportunidade que me ofereceram para traçar aqueles caminhos e lutas.

\section{NOTAS}

${ }^{1}$ Helena Lewin, doutora em sociologia pela USP (1981), é professora da Uerj. Publicou diversos livros e artigos sobre identidade judaica.

${ }^{2}$ Charles River é um rio que separa as cidades de Boston e Cambridge (Massachusetts), colocando em lados opostos a Faculdade de Saúde Pública e Arts and Sciences de Harvard.

${ }^{3}$ Paul Starr é um sociólogo norte-americano, professor da Universidade de Princeton. No início dos anos 1980, publicou uma das mais influentes obras sobre a medicina nos EUA, trabalho que lhe rendeu amplo reconhecimento e prêmios concedidos por diversos organismos. No início dos anos 1990, Starr se tornaria conselheiro do então presidente da República Bill Clinton para a construção de um plano de reforma do sistema de saúde daquele país.

${ }^{4}$ Esping-Andersen é um sociólogo dinamarquês, professor da Universidade Pompeu Fabra, Barcelona, Espanha. Notabilizou-se pelos seus estudos sobre o Estado de bem-estar social no continente europeu, tornando-se, desde o início dos anos 1980, uma importante referência para os estudiosos acerca das políticas sociais.

${ }^{5}$ Nathan Keyfitz (1913-2010), matemático formado pela McGill University (1934) e doutor em sociologia pela University of Chicago (1952), é considerado pioneiro na aplicação de ferramentas matemáticas em pesquisa no campo da demografia.

${ }^{6}$ Trata-se de um organismo não governamental internacional criado em 1952 com foco em pesquisa nos campos das ciências sociais, biomedicina e saúde pública. Teve papel de destaque nas investigações sobre HIV/Aids e saúde reprodutiva. 
${ }^{7}$ Elza Salvatori Berquó é professora emérita da Faculdade de Saúde Pública da USP. Demógrafa e PhD em bioestatística pela Columbia University (1958), foi responsável pela produção de estudos populacionais clássicos para a demografia brasileira, entre os quais se destacam os relacionados à reprodução humana.

${ }^{8}$ John Wyon (1918-2004), inglês, foi professor por várias décadas da Escola de Saúde Pública de Harvard, dedicava especial atenção aos programas de contenção populacional de países asiáticos e aos programas de saúde da comunidade.

${ }^{9}$ O chamado Khanna Study foi um experimento de controle populacional conduzido no distrito de Ludhiana, em Punjab, Índia. Ele se inscreve nas iniciativas do governo da Índia, em articulação com defensores do controle em âmbito internacional, de construção, a partir dos anos 1950, de uma política oficial de limitação populacional naquele país.

${ }^{10}$ Dom Hélder Pessoa Câmara (1909-1999) foi um bispo católico, arcebispo emérito de Olinda e Recife. Foi um dos fundadores da Conferência Nacional dos Bispos do Brasil e grande defensor dos direitos humanos durante a ditadura civil-militar brasileira. Em reconhecimento à sua atuação, recebeu diversos prêmios nacionais e internacionais.

${ }^{11}$ Graduada em sociologia e física, mestre em administração pública e doutora em ciência política pelo Massachusetts Institute of Technology (MIT), Maria Helena Castro Santos é professora aposentada do Instituto de Relações Internacionais (Irel) da Universidade de Brasília (UnB) e pesquisadora colaboradora sênior do mesmo instituto.

${ }^{12}$ Barbara Gutman Rosenkrantz (1923-2014), historiadora da saúde pública, norte-americana, lecionou no Departamento de História da Ciência de Harvard entre 1971 e 1993. Desenvolveu trabalhos inovadores sobre história e saúde pública.

${ }^{13}$ George Rosen (1910-1977), médico, professor, administrador, editor, era especializado em saúde pública, medicina preventiva e história da medicina. Foi professor da Columbia University e da Yale University e cofundador, em 1946, do The Journal of The History of Medicine and Allied Sciences.

${ }^{14}$ Naomar Monteiro de Almeida Filho é médico, doutor em epidemiologia, professor titular de epidemiologia no Instituto de Saúde Coletiva da Universidade Federal da Bahia (Ufba). Foi reitor da Ufba e da Universidade Federal do Sul da Bahia (UFSB).

${ }^{15}$ Charles Freitas Pessanha, sociólogo pela Universidade Federal Fluminense, doutor pela USP, é professor associado da Universidade Federal do Rio de Janeiro (UFRJ). Foi por vários anos editor de Dados: Revista de Ciências Sociais, do Iuperj.

${ }^{16}$ Raymundo Faoro (1925-2003), jurista, historiador e cientista político, é autor de estudos seminais sobre patrimonialismo e burocracia no Brasil. Presidiu a Ordem dos Advogados do Brasil entre 1977 e 1979, e foi membro da Academia Brasileira de Letras.

${ }^{17}$ Doutor em ciência política, Wanderley Guilherme dos Santos foi um dos fundadores do Iuperj, onde atuou como professor com contribuições fundamentais para o estudo de teoria política, democracia e políticas sociais no Brasil e para a institucionalização da ciência política como campo disciplinar.

${ }^{18}$ Fernando Henrique Cardoso é sociólogo, doutor em sociologia e livre-docente pela USP, onde lecionou. Desenvolveu estudos importantes sobre escravismo e elites industriais. É especialmente reconhecido por sua contribuição à teoria da dependência. Exerceu os cargos de senador e presidente da República Federativa do Brasil.

${ }^{19}$ Octavio Ianni (1926-2004) era sociólogo. Lecionou na USP, na Pontifícia Universidade Católica de São Paulo, e desenvolveu atividades de investigação no Cebrap. É autor especialmente importante nos estudos sobre escravidão e desenvolvimento capitalista no Brasil.

${ }^{20}$ A norte-americana Theda Skocpol, socióloga e cientista política, atualmente é professora da cadeira de sociologia e governo na Harvard University. É conhecida por seus estudos sobre o Estado e pelas abordagens da sociologia histórica e do chamado institucionalismo.

${ }^{21}$ Rosemary C.R. Taylor é professora de sociologia e saúde da comunidade na Tufts University, em Boston, EUA, com contribuições aos estudos comparativos em história das doenças e das políticas de saúde a partir de uma perspectiva sociológica.

22 Ellen Immergut, cientista política, exerceu a docência no MIT entre 1987 e 1994, com estudos comparativos importantes sobre políticas sociais e de saúde.

${ }^{23}$ Alfredo Wagner Berno de Almeida é antropólogo, formado pelo Museu Nacional, especialmente dedicado a cartografia social nos contextos nordestinos e amazônicos. 
${ }^{24}$ Lina Faria é doutora em saúde coletiva pelo Instituto de Medicina Social da Uerj e professora da Universidade Federal do Sul da Bahia.

${ }^{25}$ Paul Singer (1932-2018), economista pela USP, fez contribuições nas áreas de desenvolvimento urbano, capitalismo e políticas sociais.

${ }^{26}$ Isaac Kerstenetzky (1926-1991), economista brasileiro, foi presidente do Instituto Brasileiro de Geografia e Estatística (IBGE) de 1970 a 1979.

${ }^{27}$ Ruth Cardoso (1930-2008), doutora em antropologia pela Faculdade de Filosofia, Letras e Ciências Humanas da USP, foi professora da USP e diretora do Cebrap. Desenvolveu importantes estudos sobre movimentos feministas, étnico-raciais e de orientação sexual.

${ }^{28}$ Everardo Nunes é educador e sociólogo pela USP. Produziu contribuições importantes sobre a história da medicina social na América Latina e no Brasil.

${ }^{29} \mathrm{O}$ argentino Juan César Garcia (1932-1984), médico e sociólogo, foi liderança da medicina social latinoamericana nas décadas de 1960 e 1970, exercendo suas atividades a partir da área de desenvolvimento de recursos humanos da Organização Pan-americana da Saúde (Opas).

${ }^{30}$ Florestan Fernandes (1920-1995), sociólogo pela USP, foi um dos mais importantes intelectuais do período de institucionalização das ciências sociais no Brasil, com contribuições importantes para a análise da sociedade brasileira, da mudança social e do subdesenvolvimento.

${ }^{31}$ Maria Cecília Ferro Donnangelo (1940-1983), doutora em sociologia pela USP, sob orientação de Luiz Pereira, foi professora do Departamento de Medicina Preventiva da Faculdade de Medicina da USP. É autora de contribuições teóricas da emergente saúde coletiva nos anos 1970 e 1980.

${ }^{32}$ Madel Therezinha Luz é doutora em ciência política pela USP. É professora aposentada da Uerj e da UFRJ. Sua produção inclui temas como mercado de trabalho e profissões de saúde, instituições de saúde e racionalidades em saúde.

${ }^{33}$ Luiz Pereira (1933-1985) foi um pedagogo e sociólogo, tendo sido professor da Faculdade de Filosofia, Letras e Ciências Sociais da USP.

${ }^{34}$ Luis Eugenio Portela Fernandes de Souza, médico e doutor em planejamento em saúde pela Universidade de Montreal, atua como professor do ISC/Ufba.

${ }^{35}$ Neiva Vieira da Cunha, socióloga com doutorado em antropologia no Centre D'Etudes des Mouvements Sociaux de Paris, atua como professora na Uerj.

${ }^{36}$ Graduado em ciências sociais pela Unicamp (1982), com mestrado (1987) e doutorado (1995) em antropologia social pelo Museu Nacional/UFRJ.

${ }^{37}$ Graduada em ciências sociais pela Universidade Federal de Juiz de Fora (1960), com mestrado em antropologia social pela UFRJ (1969) e doutorado em sociologia pela Université de Paris, Nanterre (1973).

38 O Serviço Especial de Saúde Pública (Sesp) surgiu em 1942, a partir da cooperação bilateral entre os governos do Brasil e dos EUA. Seu objetivo foi controlar doenças, com foco na malária, nas regiões exportadoras de borracha. Nos anos seguintes, o programa se ampliou para a região do Vale do Rio Doce e outras regiões do país, pouco a pouco desenvolveria crescente expertise na organização de serviços locais de saúde e formação de recursos humanos para o setor.

${ }^{39}$ Discípulo de Franz Boas, o antropólogo estadunidense Charles Wagley (1913-191) dirigiu o Instituto de Estudos Latino-americanos da Universidade de Columbia. Brasilianista, teve papel de destaque tanto na análise do Brasil rural no pós-guerra quanto na construção da antropologia social brasileira. Elaborou importantes pesquisas sobre grupos de língua tupi na Amazônia e aculturação e mudanças culturais desses mesmos grupos. Foi diretor do Sesp na área de Educação para a Saúde.

${ }^{40}$ Antônio Sérgio da Silva Arouca (1941-2003), médico pela USP, foi professor da Escola Nacional de Saúde Pública - que após a sua morte recebeu o seu nome - e presidente da Fundação Oswaldo Cruz. Foi uma liderança intelectual e política importante do movimento pela reforma da saúde no Brasil a partir de meados da década de 1970, tendo sido deputado federal no momento da elaboração da Constituição de 1988 .

${ }^{41}$ José Nun, advogado e cientista político argentino, foi secretário nacional de Cultura na década de 2000. Autor de vasta produção, esteve envolvido em estudos sobre racionalidade política, mudança social e marginalidade. 
${ }^{42}$ Darcy Ribeiro (1922-1997), antropólogo pela Escola de Sociologia e Política de São Paulo, foi um intelectual dedicado aos temas indígenas e à educação pública no Brasil. Foi criador e reitor da Universidade de Brasília, ministro da Educação e Cultura, vice-governador do Rio de Janeiro e senador pelo mesmo estado.

${ }^{43}$ Eduardo Stotz é doutor em saúde pública pela Fundação Oswaldo Cruz e pesquisador titular na mesma instituição. Desenvolve pesquisas no campo da saúde pública, atuando principalmente nos temas ligados a educação popular, movimentos sociais e saúde.

${ }^{44}$ José de Assis Valente (1911-1958) foi ilustrador e compositor brasileiro. Um de seus principais sucessos foi a música "Brasil pandeiro".

${ }^{45}$ João Pacheco de Oliveira Filho é doutor em antropologia social e professor titular na UFRJ (Museu Nacional). Realizou pesquisas nas temáticas de indigenismo, política e territorialidade. Nos últimos anos, tem se dedicado a questões ligadas à antropologia do colonialismo e à antropologia histórica, desenvolvendo trabalhos relacionados à formação do Brasil.

${ }^{46} \mathrm{O}$ antropólogo Terri Valle de Aquino produziu trabalhos pioneiros sobre os índios kaxinawá. Também trabalhou intensamente na organização de movimentos sociais dos povos indígenas da Amazônia.

${ }^{47}$ Médico e historiador da medicina, Lycurgo Santos Filho (1910-1998) deixou uma grande quantidade de estudos sobre diversos aspectos da história da medicina brasileira. É considerado pioneiro e um expoente da história médica da medicina brasileira.

${ }^{48}$ Diego Armus é um historiador argentino que vive e trabalha nos EUA, lecionando no Swarthmore College, na Pensilvânia.

${ }^{49}$ Nisia Trindade Lima, mestre em ciência política, doutora em sociologia pelo Iuperj, foi vice-presidente de Ensino, Informação e Comunicação da Fiocruz (2011-2016) e atualmente é presidente da Fundação Oswaldo Cruz (2017- ).

\section{REFERÊNCIAS}

CUNHA, Neiva Vieira da.

Viagem, experiência e memória: narrativas de profissionais da saúde pública dos anos 30. Santa Catarina: Edusc. 2005.

HOCHMAN, Gilberto.

A era do saneamento: as bases da política de saúde pública no Brasil. São Paulo: Hucitec; Anpocs. 1998.
LEAL, Victor Nunes.

Coronelismo, enxada e voto. São Paulo:

Companhia das Letras. 2012.

STARR, Paul.

The social transformation of American medicine. New York: Basic Books. 1982.

ROSENKRANTZ, Barbara G.

Public health and the State: changing views in Massachusetts, 1832-1936. Cambridge: Harvard

University Press. 1972.

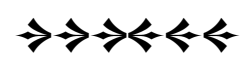

